\title{
Inorganic Impurity
}

National Cancer Institute

\section{Source}

National Cancer Institute. Inorganic Impurity. NCI Thesaurus. Code C134001.

Any unwanted inorganic compound generated during the manufacturing process of a particular substance or product. 